\title{
Sensitive detection of anaerobic monochlorobenzene degradation using stable isotope tracers
}

Ivonne Nijenhuis $^{1}$, Nicole Stelzer ${ }^{1}$, Matthias Kästner ${ }^{2}$, Hans-H. Richnow ${ }^{1}$

UFZ Centre for Environmental Research Leipzig-Halle; Permoserstr. 15; 04318

Leipzig; Department ${ }^{1}$ Isotope Biogeochemistry (ISOBIO) and ${ }^{2}$ Bioremediation (BIOREM)

\section{METHODS}

\section{Analysis}

GC-MS. For identification and structural characterization of FAME by GC-MS a Hewlett Packard 6890 gas chromatograph coupled to a 5973 quadropole mass spectrometer (Agilent, Palo Alto, USA) was used. The carboxylic acid fraction was separated on a BPX-5 column (30 m*0.32 mm*0.25 $\mu \mathrm{m})$ (SGE, Darmstadt, Germany) with a temperature program of $120^{\circ} \mathrm{C}$ initial temperature for 4 min, heat at $4{ }^{\circ} \mathrm{C} \min ^{-1}$ to $250^{\circ} \mathrm{C}$, heat at $20^{\circ} \mathrm{C} \mathrm{min}^{-1}$ to $300^{\circ} \mathrm{C}$, and hold for $10 \mathrm{~min}$. FAME were identified by co-injection of an authentic standard mix (bacterial acid methyl ester mix, Supelco) and concentrations of FA were quantified relatively to the internal standard (Henicosanoic acid, C21:0). The fatty acids are designated in the form of $A: B$ where $\mathrm{A}$ is the number of carbon atoms, B is the number of double bonds.

GC-FID For detection of MCB, ethene and the chlorinated ethenes in the microcosms and enrichment cultures, gas chromatography with flame ionization detection (GCFID) (gas chromatograph:Varian Chrompack CP-3800, Middelburg, The 
Netherlands), equipped with a 30m x 0.53mm GS-Q column (J\&W Scientific, Waldbronn, Germany), was applied. The temperature program used was as follows: 1 $\min$ at $100^{\circ} \mathrm{C}, 50^{\circ} \mathrm{C} \min ^{-1}$ to $225^{\circ} \mathrm{C}$, hold $2.5 \mathrm{~min}$. The FID was operated at $250^{\circ} \mathrm{C}$ and helium was used as carrier gas (10 psi). The injection was automated using an HP 7694 headspace auto sampler (Hewlett Packard, Palo Alto, USA), adding $0.5 \mathrm{ml}$ headspace samples to $10 \mathrm{ml}$ auto sampler vials flushed with helium, which were closed with a Teflon coated butyl rubber septum and crimped.

GC-C-IRMS. The carbon isotope composition of the carboxylic acids fractions was analyzed using a gas chromatography-combustion-isotope-ratio-monitoring-massspectrometer system (GC-C-IRMS). The system consists of a gas chromatograph (6890 Series, Agilent Technology, Palo Alto, USA) coupled via a Conflow III interface (ThermoFinnigan, Bremen, Germany) to a MAT 252 mass spectrometer (ThermoFinnigan, Germany). The performance was described previously $(1,2)$. A BPX-5 column (50 m*0.32 mm*0.5) (SGE, Darmstadt, Germany) was used for chromatographic separation with helium as carrier gas at a flow rate of $1.5 \mathrm{~mL} \mathrm{~min}{ }^{-1}$ and a temperature program with initial temperature of $60^{\circ} \mathrm{C}$ for $2 \mathrm{~min}$, heat at $20^{\circ} \mathrm{C}$ $\min ^{-1}$ to $120^{\circ} \mathrm{C}$, heat at $2{ }^{\circ} \mathrm{C} \min ^{-1}$ to $300{ }^{\circ} \mathrm{C}$, and hold for $20 \mathrm{~min}$ (3). The analysis of chlorobenzene on the same system was described previously (4). For separation of methane and $\mathrm{CO}_{2}$ the same system was used equipped with a Poraplot Q column (25 m x 0.32 mm ID, $1 \mu \mathrm{m}$ film; Chrompack, Middelburg, The Netherlands). For the separation on a Poraplot column, the temperature was set to $40^{\circ} \mathrm{C}$ isothermally. 50 $100 \mu \mathrm{l}$ headspace samples were injected at 1:5 to 1:50 split ratio. The carbon isotope ratio of fatty acids is reported in $\delta$-notation (per mill) relative to the Vienna Pee Dee Belemnite standard (V-PDB) with known isotopic composition (5). 


\section{REFERENCES}

(1) Richnow, H. H.; Annweiler, E.; Michaelis, W.; Meckenstock, R. U. Microbial in situ degradation of aromatic hydrocarbons in a contaminated aquifer monitored by carbon isotope fractionation J Contam Hydrol 2003, 65, 59-72.

(2) Richnow, H. H.; Meckenstock, R. U.; Reitzel, L. A.; Baun, A.; Ledin, A.; Christensen, T. H. In situ biodegradation determined by carbon isotope fractionation of aromatic hydrocarbons in an anaerobic landfill leachate plume (Vejen, Denmark) $J$ Contam Hydrol 2003, 64, 59-72.

(3) Miltner, A.; Richnow, H.-H.; Kopinke, F.-D.; Kastner, M. Assimilation of $\mathrm{CO} 2$ by soil microorganisms and transformation into soil organic matter Org Geochem 2004, 35, 1015.

(4) Kaschl, A.; Vogt, C.; Uhlig, S.; Nijenhuis, I.; Weiss, H.; Kästner, M.; Richnow, H. H. Isotopic fractionation indicates anaerobic monochlorobenzene biodegradation Environ Toxicol Chem 2005, 24, 1315-1324.

(5) Anonymous " IAEA-TECHDOC-825, International Atomic Energy Agency," 1995. 


\section{Investigation of in situ microcosms}

The in situ microcosms were incubated in a multilevel fashion, attached along the complete length of the multi-level sampling system (MLPS) at 6 depths (m1-m6) at 8.1, 14.5, 16.5, 18.5, 20.5 and 21.9 m depth below the surface. The water table was located at approx. 4 meters below the surface. The in situ microcosm sets, consisting of a ${ }^{12} \mathrm{C}-\mathrm{MCB}$ amended microcosm, an unloaded microcosm (blank), a ${ }^{13} \mathrm{C}-\mathrm{MCB}$ amended microcosm and a further blank were positioned over a depth of about $80 \mathrm{~cm}$. The space between the individual in situ microcosms of each level was approx. $20 \mathrm{~cm}$ (See Fig. S1). According to previous experience, this distance is sufficient to allow the packer membrane to separate the microcosms within the well and prevent circulation of water between the individual microcosms. However, water may circulate between different levels through the filter material of the well screens or the surrounding sediments.

During incubation, the Bio-Sep ${ }^{\circledR}$ bead material in the unloaded microcosms can adsorb contaminants from the surrounding ground water and aquifer microorganisms may grow on the surfaces using the adsorbed contaminants as carbon source. The isotope composition of contaminants adsorbed from the groundwater to the blank microcosm is commonly identical to the isotope composition of individual contaminants in the aquifer. On one of the blank experiments at the level m6 the isotope signature of MCB was comparable to the surrounding groundwater (-25 \% \pm 0.5), however, benzene was significantly enriched in ${ }^{13} \mathrm{C}(+560 \%$ o ) (Fig. S2). The label in benzene can only stem from one of the ${ }^{13} \mathrm{C}$-substrate amended microcosms. Because the packer system should have prevented direct circulation in the open tube of the well, the ${ }^{13} \mathrm{C}$-labeled material must have been transported through the filter section of the well or the surrounding sediments from the ${ }^{13} \mathrm{C}$ amended microcosm to 
the blank over a distance of at least $20 \mathrm{~cm}$ (See Fig. S1). The relative amounts of MCB and benzene adsorbed during incubation on the non amended microcosm were similar with the relative benzene concentrations on the blank in situ microcosm being about one third of the MCB concentration. (See Fig. S2). Although $\left[{ }^{13} \mathrm{C}_{6}\right]$-benzene was already present in trace concentrations $(0.02 \%)$ in the commercial $\left[{ }^{13} \mathrm{C}_{6}\right]-\mathrm{MCB}$, it is unlikely that the impurity of the chemical was the source of labeled benzene on the blank microcosm. Because benzene and MCB have similar physico-chemical properties, both compounds should be transported in the same way and a separation of both chemicals upon diffusion in or transport with the groundwater is very unlikely. Therefore, transport of labeled benzene without the co-transport of labeled MCB seems to be unlikely and the adsorption of small parts of the substrate $\left(\left[{ }^{13} \mathrm{C}_{6}\right]-\mathrm{MCB}\right.$ with $0.02 \%{ }^{13} \mathrm{C}$-benzene) and the mixture of $\mathrm{MCB}$ and benzene from the aquifer contamination would lead to a very different isotope signatures. The GC-C-IRMS analysis showed that the concentrations of benzene and MCB were in a similar range but only benzene contained the ${ }^{13} \mathrm{C}$ label (Figure S2). Therefore it is unlikely that the labeled benzene was derived from the impurity in the substrate. It is likely that the ${ }^{13} \mathrm{C}$-labeled benzene was formed via dehalogenation during transport from the ${ }^{13} \mathrm{C}$ amended microcosms to the blank. The relatively high concentration of MCB and benzene on the blank may further indicate that benzene may be formed to some extent during reductive dehalogenation in this part of the aquifer. It should be mentioned that we also found ${ }^{13} \mathrm{C}$-labeled benzene in the laboratory microcosms but because of the impurity in the ${ }^{13} \mathrm{C}-\mathrm{MCB}$ preparation we could not prove its production. However, benzene did not accumulate in these laboratory microcosms and disappeared over time. 


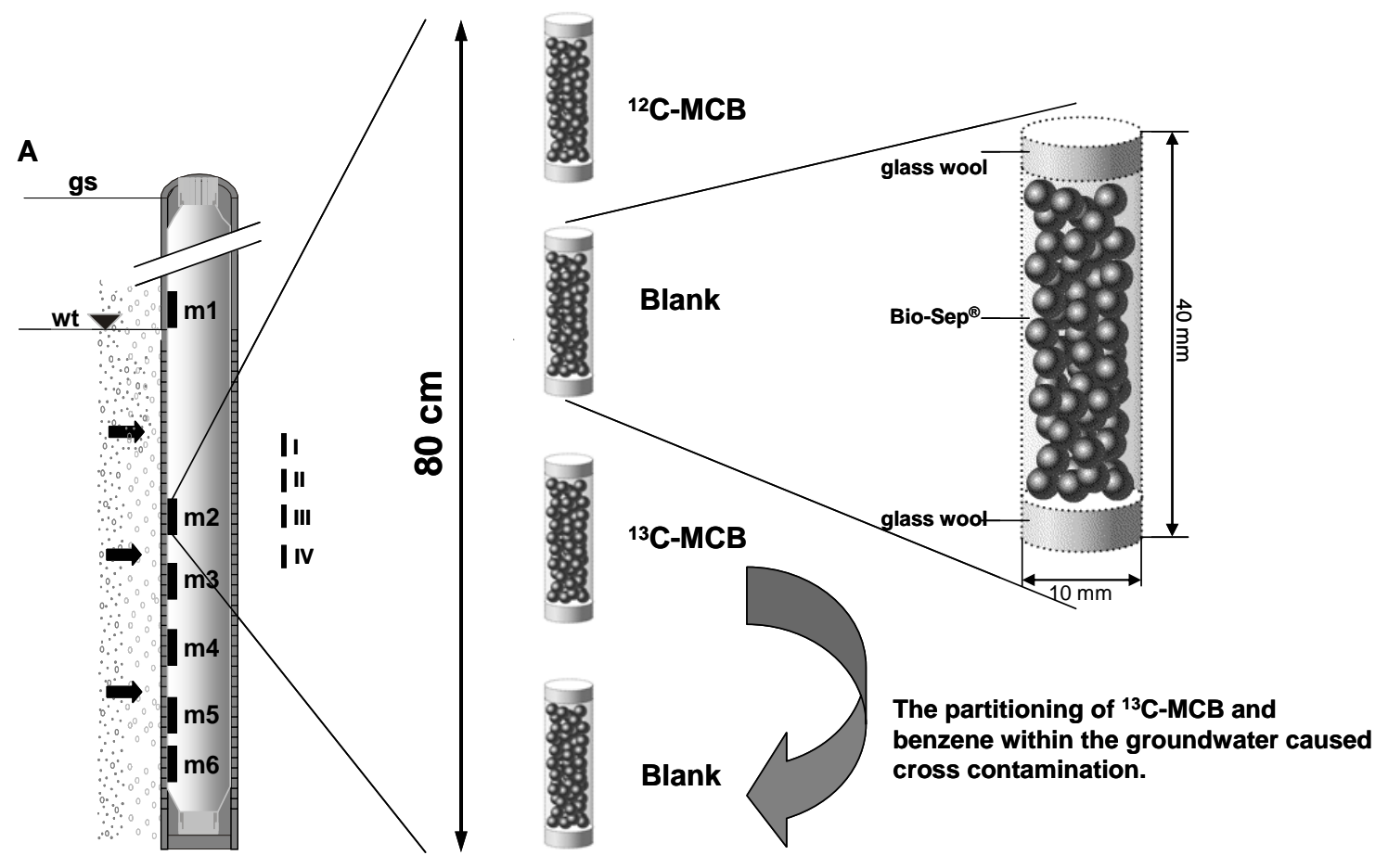

\section{Figure S1:}

Detailed lay-out of the in situ microcosm experiment. The in situ microcosms were incubated at 6 levels (m1-m6) and each set consisted of a ${ }^{12} \mathrm{C}-\mathrm{MCB}$ loaded, a blank, a $\left[{ }^{13} \mathrm{C}_{6}\right]$-MCB-loaded and another blank microcosm. The overall distance of each set was about $80 \mathrm{~cm}$, each microcosm was located approx. $20 \mathrm{~cm}$ from the next. 


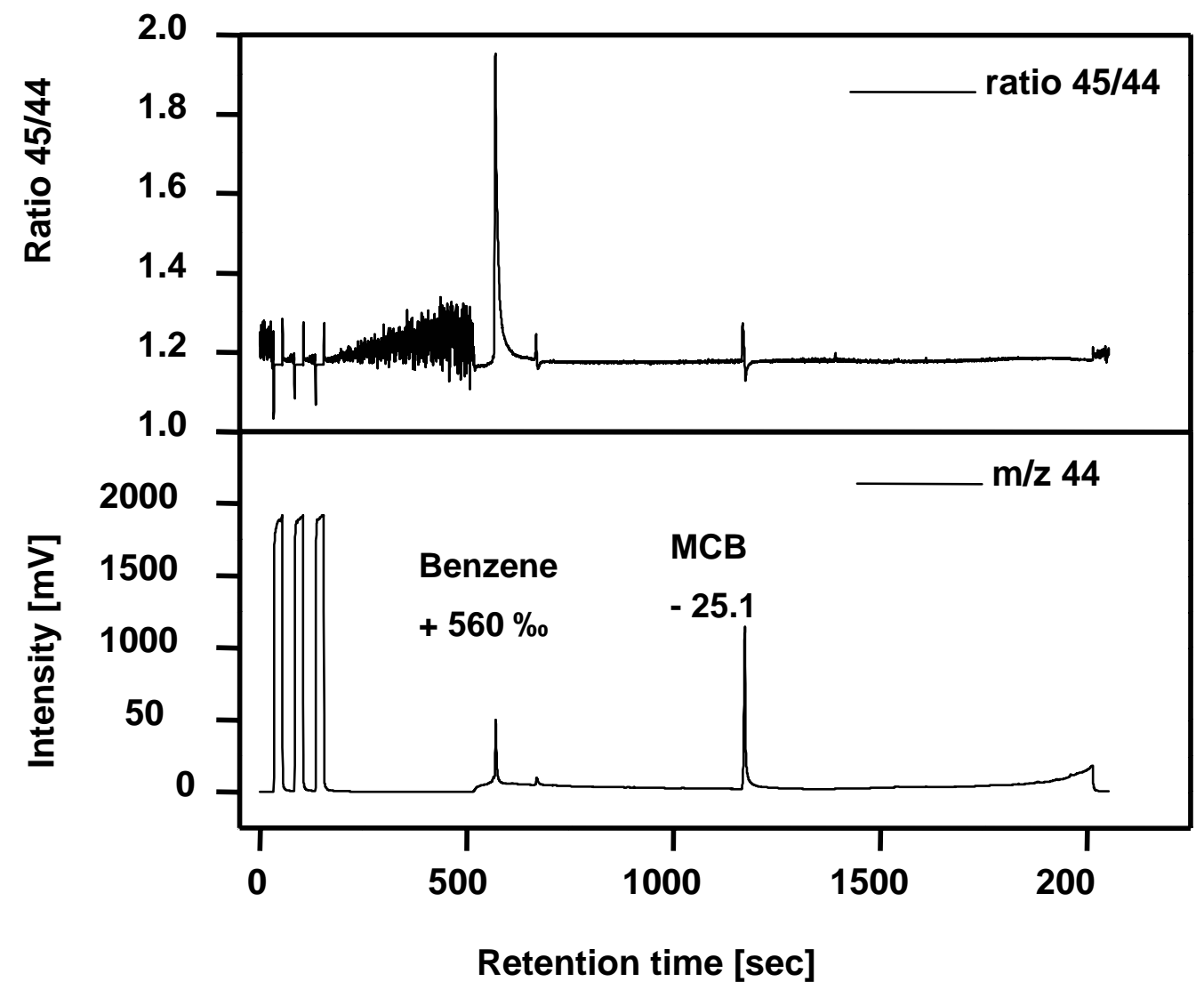

Figure S2:

GC-C-IRMS-chromatogram of the dichloromethane extract from a Blank (nonloaded) in situ microcosm (m6) incubated at SAF4. A: Only the benzene shows an enrichment in ${ }^{13} \mathrm{C}$ indicated by the increase in the ratio of $45 / 44$ whereas the MCB shows an isotope signature within the range of natural abundance. B: The relative concentration of both compounds is displayed $\left(\mathrm{m} / \mathrm{z} 44={ }^{12} \mathrm{CO}_{2}\right.$. In addition the $\delta^{13} \mathrm{C}$ values of MCB and benzene are indicated in the lower panel. 


\section{Confirmation of anoxic conditions in the laboratory microcosms:}

Resazurin was used as a redox indicator to monitor anaerobic conditions throughout the microcosm experiment. At $-0.051 \mathrm{mV}$ and below at neutral $\mathrm{pH}$, resazurin will be colorless indicating anaerobic conditions while at higher reduction potential it will turn to pink color (Tratnyek et al, 2001). Visual inspection of the microcosms on a regular basis indicated the presence of anoxic conditions. The presence of redox active compounds ( $\mathrm{Fe}(\mathrm{II})$ and $\mathrm{S}^{2-}$ ) (Table S1) which would be abiotically oxidized in the presence of oxygen, support the presence of anoxic conditions in the microcosms. Sulfide concentrations are in the same range, or sometimes higher, in the microcosms after 800 days compared to the original groundwater. Dissolved Fe(II) concentrations were generally found to be lower compared to the groundwater, but the total Fe(II) concentrations may be underestimated since FeS precipitates may form. Both the visual inspection using resazurin and the presence of Fe(II) and sulfide in the microcosms support the presence of anoxic conditions in the microcosms throughout the experiment.

\section{Reference:}

Tratnyek, P. G.; Reilkoff, T. E.; Lemon, A. W.; Scherer, M. M.; Balko, B. A.; Feik, L. M.; Henegar, B. D. Visualizing redox chemistry: probing environmental oxidationreduction reactions with indicator dyes Chem Educator 2001, 6, 172-179. 


\section{Table S1:}

Soluble iron (II) and total sulfide concentrations were determined to confirm the presence of anaerobic conditions and redox buffers in our microcosms. Shown are values for the original groundwater from well SAF11 and in the anaerobic microcosms prepared from this groundwater at the end of the experiment (approx. 800 days). *Values for the microcosm depicted in Figure 2 of the main manuscript. **Data from Kaschl, A.; Vogt, C.; Uhlig, S.; Nijenhuis, I.; Weiss, H.; Kästner, M.; Richnow, H. H. Isotopic fractionation indicates anaerobic monochlorobenzene biodegradation Environ Toxicol Chem 2005, 24, 1315-1324.

\begin{tabular}{|c|c|c|}
\hline Sample & $\begin{array}{c}\text { Fe (II) } \\
\mu m o l L^{-1}\end{array}$ & $\begin{array}{c}\mathrm{S}^{2-} \\
\mu \mathrm{mol} \mathrm{L}^{-1}\end{array}$ \\
\hline $\begin{array}{l}\text { SAF11 } \\
\text { groundwater }\end{array}$ & $21^{\star *}$ & $22^{\star *}$ \\
\hline $\begin{array}{l}\text { SAF11 [labeled] } \\
\text { microcosms live }\end{array}$ & $\begin{array}{l}3.8^{\star} \\
3.6 \\
4.2 \\
3.9\end{array}$ & $\begin{array}{c}26.3^{*} \\
17.5 \\
33.3 \\
38.5\end{array}$ \\
\hline $\begin{array}{l}\text { SAF11 [unlabeled] } \\
\text { microcosms live }\end{array}$ & $\begin{array}{l}4.1 \\
3.8 \\
3.6 \\
4.5 \\
4.2\end{array}$ & $\begin{array}{c}0 \\
47.4 \\
56 \\
36.8 \\
38.5\end{array}$ \\
\hline $\begin{array}{l}\text { SAF11 } \\
\text { microcosms } \\
\text { killed control }\end{array}$ & $\begin{array}{l}8.2 \\
6.1\end{array}$ & $\begin{array}{l}0 \\
0\end{array}$ \\
\hline
\end{tabular}

